\title{
Associação de fosfatos e inoculação com Bacillus subtilis e seu efeito no crescimento e desempenho produtivo do feijoeiro
}

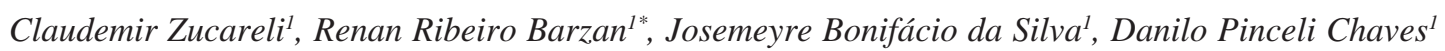

10.1590/0034-737X201865020011

\begin{abstract}
RESUMO
O feijoeiro é uma cultura responsiva à aplicação de fósforo $(\mathrm{P})$ e estudos são necessários para identificar manejos de fornecimento que minimizem a dependência de fosfatos solúveis, os quais têm uma obtenção onerosa e baixo efeito residual. O objetivo do estudo foi avaliar o crescimento e o desempenho produtivo do feijoeiro em resposta à aplicação isolada ou associada de fontes naturais e solúvel de fósforo, na presença e ausência de inoculação com Bacillus subtilis. O experimento foi conduzido em casa de vegetação, utilizando um Latossolo Vermelho com teor inicial de P de $6,61 \mathrm{mg} \mathrm{dm}^{-3}$. O delineamento foi inteiramente casualizado, em esquema fatorial $6 \times 2$, estudando-se as seguintes fontes de fósforo, na dose equivalente a $120 \mathrm{~kg} \mathrm{P}_{2} \mathrm{O}_{5}$ ha $^{-1}$ : superfosfato triplo (SFT, solúvel), Itafós (ITA, natural não reativo), Gafsa (GAF, natural reativo), SFT + ITA, SFT + GAF e um controle (sem adubação com P); com e sem inoculação com B. subtilis $\left(10^{9}\right.$ células $\left.\mathrm{mL}^{-1}\right)$ e quatro repetições. Melhores resultados de crescimento da parte aérea e raízes, além do desempenho produtivo, foram obtidos com o uso do SFT, isolado ou combinado com ITA e GAF. Para a fonte solúvel, a inoculação com B. subtilis também promoveu maior crescimento, porém não influenciou a produtividade de grãos, que foi incrementada em função da inoculação apenas quando se utiliza a fonte ITA isoladamente.
\end{abstract}

Palavras-chave: rizobactérias; fósforo; componentes de produção.

\section{ABSTRACT}

\section{Association of phosphates and inoculation with Bacillus subtilis and its effect on the growth and productive performance of common bean}

The common bean crop is responsive to phosphorus (P) fertilization, and studies are needed to identify supply managements that minimize the dependency of soluble phosphates, which are costly and have low residual effect. The aim of the study was to evaluate the growth and productive performance of the common bean crop as affected by sole or associated applications of soluble and rock phosphates, in the presence and absence of Bacillus subtilis inoculation. The experiment was carried out in pots in a greenhouse, using a Red Latosol with an initial concentration of $6.61 \mathrm{mg} P$ $\mathrm{dm}^{-3}$. The experimental design was completely randomized in a factorial scheme $6 \times 2$, in which the sources of phosphorus were studied, at a dose equivalent to $120 \mathrm{~kg} \mathrm{P}_{2} \mathrm{O}_{5}$ ha' $^{-1}$ : 'triple superphosphate' (TSP, soluble), 'Itafós' (ITA, rock), 'Gafsa' (GAF, rock), TSP + ITA, TSP + GAF, and one control (no P fertilizer) - with and without inoculation of Bacillus subtilis and four replications. Better results for shoot and root growth, besides productive performance, were obtained with the application of TSP, solely or combined with ITA and GAF. For the soluble source, the inoculation with $B$. subtilis also promoted higher growth, although not influencing the grain yield, which was only increased by inoculation when ITA was solely used.

Keywords: rhizobacteria; phosphorus; yield components.

Submetido em 30/10/2016 e aprovado em 01/02/2018.

'Universidade Estadual de Londrina, Departamento de Agronomia, Londrina, Paraná, Brasil. claudemircca@uel.br; renan_barzan@hotmail.com; josibonifacio@uel.br; danilochavesmt@gmail.com

*Autor para correspondência: renan_barzan@hotmail.com 


\section{INTRODUÇÃO}

No Brasil, uma das razões para a baixa produtividade do feijoeiro (Phaseolus vulgaris L.) é a carência generalizada de fósforo $(\mathrm{P})$ disponível no solo, devido à elevada adsorção específica na fração argila dos solos de carga variável (Valladares et al., 2003). Com isso, a produção do feijoeiro apresenta resposta à aplicação do nutriente no solo (Valderrama et al., 2009; Viana et al., 2011; Cunha et al., 2014).

A demanda de $\mathrm{P}$ pelo feijoeiro, no entanto, é considerada baixa, de $16 \mathrm{~kg} \mathrm{ha}^{-1}$, quando comparada a $112 \mathrm{~kg} \mathrm{ha}^{-1}$ de nitrogênio $(\mathrm{N})$ e $138 \mathrm{~kg} \mathrm{ha}^{-1}$ de potássio $(\mathrm{K})$ (Pegoraro et $a l ., 2014)$. O P aumenta a produção de matéria seca da parte aérea, o número de vagens e a massa de grãos do feijoeiro, sendo que o número de vagens por unidade de área é o componente que mais contribui para o aumento da produtividade (Fageria et al., 2003; Zucareli et al., 2006).

Dentre as fontes de P, destacam-se os fosfatos solúveis como o superfosfato triplo (SFT), que tem elevada concentração do elemento ( $45 \%$ de $\mathrm{P}_{2} \mathrm{O}_{5}$ total e $40,4 \%$ de $\mathrm{P}_{2} \mathrm{O}_{5}$ solúvel em ácido cítrico a $2 \%$ ) e os fosfatos naturais, que são menos concentrados e pouco solúveis em água. Estas características levam a diferenças acentuadas na velocidade de liberação para as plantas do $\mathrm{P}$ proveniente dessas fontes, bem como no potencial de fixação do elemento no solo (Korndörfer et al., 1999).

Os fosfatos naturais podem ainda ser classificados conforme a reatividade, variável de acordo com a estabilidade da estrutura cristalina da rocha de origem, sendo as fontes brasileiras normalmente pouco reativas (Korndörfer et al., 1999). O fosfato natural de Gafsa, oriundo da Tunísia, é considerado reativo e possui $29,6 \%$ de $\mathrm{P}_{2} \mathrm{O}_{5}$ total e $10 \%$ de $\mathrm{P}_{2} \mathrm{O}_{5}$ solúvel em ácido cítrico a $2 \%$. Por outro lado, o fosfato brasileiro Itafós é de baixa reatividade, além de ser menos concentrado, com 23,2\% de $\mathrm{P}_{2} \mathrm{O}_{5}$ total e 5,5\% de $\mathrm{P}_{2} \mathrm{O}_{5}$ solúvel em ácido cítrico a $2 \%$ (Brasil, 2007). Em face do iminente esgotamento das reservas mundiais de rochas fosfáticas em um futuro não muito distante (Pantano et al., 2016), o estudo de estratégias para o uso mais eficiente do fósforo na agricultura é fundamental para promover uma maior sustentabilidade da atividade e segurança alimentar da população.

Nesse sentido, misturas de fontes de P utilizando fosfatos naturais com solúveis já têm se mostrado uma alternativa agronômica e economicamente viável no fornecimento do nutriente para algumas culturas como a soja e o milho (Piaia et al., 2002; Franzini et al., 2009; Oliveira Júnior et al., 2011), bem como o uso de inoculantes com Rizobactérias Promotoras de Crescimento de Plantas (RPCPs), que podem desempenhar papel importante na disponibilização e reciclagem de nutrientes (Coelho et al., 2007).
Os microrganismos podem solubilizar e mineralizar o $\mathrm{P}$ de fontes orgânicas e inorgânicas e serem usados como inoculantes visando o aumento da disponibilidade de $\mathrm{P}$ para as plantas (Richardson, 2001). Os microrganismos solubilizadores de fosfatos desempenham papel importante na liberação de formas inorgânicas de fósforo (Ca-P, Al-Pe Fe-P), aumentando o teor de $\mathrm{P}$ na solução, o que propicia melhor crescimento e maior rendimento das plantas (Chabot et al., 1996).

Diferentes espécies de rizobactérias foram identificadas como capazes de solubilizar compostos fosfatados inorgânicos (Rodriguez \& Fraga, 1999). Em uma área deficiente em fósforo, os autores Gaind \& Gaur (1991), por exemplo, relataram que a inoculação com diversas estirpes de bactérias solubilizadoras de fosfato, com destaque para Bacillus subtilis, aumentou a disponibilidade de fósforo no solo, a absorção do nutriente, a produção de biomassa de raízes e parte aérea, bem como a produtividade de grãos de feijão.

A associação de fontes naturais e solúvel de $\mathrm{P}$ pode favorecer o crescimento e a produção do feijoeiro, já que a inoculação de bactérias com ação solubilizadora de fosfato é capaz de potencializar os efeitos da fertilização fosfatada. Assim, objetivou-se avaliar o crescimento e produção do feijoeiro em resposta a fosfatos de rocha e superfosfato triplo, associados ou não, e em presença ou ausência de inoculação com Bacillus subtilis.

\section{MATERIAL E MÉTODOS}

O experimento foi conduzido em condições de casa de vegetação da Universidade Estadual de Londrina - UEL, localizada à $23^{\circ} 20^{\prime} 23.45^{\prime \prime} \mathrm{S}, 51^{\circ} 12^{\prime} 32.28^{\prime \prime}$ 'W e $532 \mathrm{~m}$ de altitude, no município de Londrina-PR. O clima da região, segundo a classificação de Köppen, é do tipo Cfa, subtropical úmido mesotérmico, com verões quentes e geadas pouco frequentes, com tendência de concentração de chuvas nos meses de verão, sem estação seca definida e com precipitação média anual de $1626 \mathrm{~mm}$. A temperatura média anual é de $21,1^{\circ} \mathrm{C}$, sendo a média das máximas de $27,3{ }^{\circ} \mathrm{C}$ e das mínimas de $16,1^{\circ} \mathrm{C}$ (IAPAR, 2016).

Para a condução do experimento, foram utilizados vasos com capacidade para $5 \mathrm{dm}^{3}$ de substrato. Os vasos foram preenchidos com o solo da região, classificado como Latossolo Vermelho Eutroférrico (Embrapa, 2013) de textura muito argilosa, com as seguintes características químicas: $\mathrm{pH}_{\mathrm{CaCl}_{2}}=4,9 ; \mathrm{Ca}^{2+}=3,51 \mathrm{cmol}_{\mathrm{c}} \mathrm{dm}^{-3} ; \mathrm{Mg}^{2+}=0,69 \mathrm{cmol}_{\mathrm{c}}$ $\mathrm{dm}^{-3} ; \mathrm{K}^{+}=0,32 \mathrm{cmol}_{\mathrm{c}} \mathrm{dm}^{-3} ; \mathrm{Al}^{3+}=0,12 \mathrm{cmol}_{\mathrm{c}} \mathrm{dm}^{-3} ; \mathrm{H}+\mathrm{Al}=$ $4,61 \mathrm{cmol}_{\mathrm{c}} \mathrm{dm}^{-3} ; \mathrm{CTC}_{\mathrm{pH} 7,0}=9,12 \mathrm{cmol}_{\mathrm{c}} \mathrm{dm}^{-3} ; \mathrm{V}=49,5 \%$; $\mathrm{P}$ Mehlich $1=6,61 \mathrm{mg} \mathrm{dm}^{-3} ; \mathrm{C}$ org. $=13,40 \mathrm{mg} \mathrm{dm}^{-3}$.

Em cada vaso, foram aplicados o equivalente a $86 \mathrm{~kg}$ $\mathrm{K}_{2} \mathrm{O} \mathrm{ha}^{-1}, 1750 \mathrm{~kg} \mathrm{CaCO}_{3}$ ha $^{-1}$ e 151,10 $\mathrm{kg} \mathrm{MgCO}_{3}$ ha $^{-1}$, visando promover o equilíbrio na saturação do complexo de 
bases, elevando-se o $\mathrm{Ca} \%, \mathrm{Mg} \%$ e $\mathrm{K} \%$ a, aproximadamente, 60, 10 e 5. A aplicação dos fosfatos foi realizada mediante incorporação ao solo e as quantidades foram calculadas de forma a proporcionar a dose final equivalente a $120 \mathrm{~kg}$ $\mathrm{P}_{2} \mathrm{O}_{5} \mathrm{ha}^{-1}(0,30 \mathrm{~g}$ por vaso). Em cada vaso, foram semeadas oito sementes de feijão do cultivar IPR Colibri, pertencente ao grupo carioca, de ciclo precoce (67 dias) e porte ereto. $\mathrm{O}$ desbaste foi realizado deixando-se duas plantas por vaso. O controle de plantas daninhas durante o ciclo da cultura foi realizado por meio de arranquio manual e a irrigação foi realizada repondo-se a água evapotranspirada por meio da pesagem dos vasos. Não houve necessidade de controle de pragas e doenças.

$\mathrm{O}$ experimento seguiu um esquema fatorial $6 \times 2 \mathrm{em}$ blocos casualizados, com 12 tratamentos e oito repetições (cada vaso sendo uma unidade experimental), sendo quatro repetições utilizadas para análises destrutivas no florescimento e outras quatro para avaliação dos componentes de produção. Foram avaliadas seis combinações de fontes de $\mathrm{P}$, constituídas por 1) controle (sem adição de P); 2) superfosfato triplo - SFT (P-solúvel); 3) fosfato de Gafsa (fosfato natural de origem sedimentar, reativo); 4) fosfato Itafós (fosfato natural de origem sedimentar, não reativo); 5) SFT + Gafsa e 6) SFT + Itafós, associadas ou não à inoculação com Bacillus subtilis. Para a inoculação foi usado um inoculante composto por glicerol $20 \%$, extrato de levedura $0,1 \%$, polímero PVP (polivinilpirrolidona) $0,1 \%$ e tampão fosfato $0,02 \mathrm{a} \mathrm{pH} \mathrm{7,0}$ contendo um isolado de Bacillus subtilis $\left(10^{9}\right.$ células viáveis $\left.\mathrm{mL}^{-1}\right)$.

A concentração de $\mathrm{P}_{2} \mathrm{O}_{5}$ total e as solubilidades em $\mathrm{H}_{2} \mathrm{O}$, citrato neutro de amônio $+\mathrm{H}_{2} \mathrm{O}\left(\mathrm{CNA}+\mathrm{H}_{2} \mathrm{O}\right)$ e ácido cítrico a $2 \%$ (A.C.) das fontes de $\mathrm{P}$ utilizadas são apresentados na Tabela 1.

No florescimento, as características avaliadas foram: índice de área foliar (IAF, $\mathrm{cm}^{2}$ ), usando um medidor de área foliar (marca Li-cor, modelo LI-3100); massa seca da parte aérea (MSPA, g) e massa seca da raiz (MSR, g), realizadas pela secagem em estufa ventilada a $65^{\circ} \mathrm{C}$ e pesagem em balança semianalítica; volume da massa seca da raiz (VR, $\mathrm{mL}$ ), medido verificando-se o volume deslocado pela introdução das raízes em uma proveta preenchida com 100 $\mathrm{mL}$ de água.
No momento da colheita, as variáveis analisadas foram: altura da inserção da primeira vagem $(\mathrm{AIV}, \mathrm{cm})$, pela determinação do comprimento do colo da planta até a inserção da primeira vagem; tamanho médio de vagem (TMV, $\mathrm{cm}$ ), medindo-se todas as vagens da planta com uso de uma fita métrica; os componentes de produção 'média do número de vagens por planta' $\left(\mathrm{NVP}, \mathrm{n}^{\circ}\right)$ e 'média do número de grãos por vagem' $\left(\mathrm{NGV}, \mathrm{n}^{\circ}\right)$, contando-se o número de vagens de todas as plantas e o número de grãos de todas as vagens; e a produtividade de grãos (PROD), calculada pela conversão da massa de grãos de cada vaso para produtividade por planta (g por planta), corrigindose a umidade para $13 \%$.

Os dados foram submetidos à avaliação dos pressupostos para utilização de estatística paramétrica (normalidade e homogeneidade de variâncias dos erros) e na sequência foi realizada análise de variância e comparação de médias pelo teste Tukey $(P<0,05)$, com auxílio do programa SISVAR v. 4.0 (Sistema para Análise de Variância) (Ferreira, 2011).

\section{RESULTADOS E DISCUSSÃO}

Para todas as características avaliadas no florescimento houve interação entre as fontes de $\mathrm{P}$ e a inoculação de Bacillus subtilis, enquanto nas variáveis da colheita, apenas houve interação para a produtividade de grãos. O número e o tamanho das vagens foram influenciados somente pelas fontes de $\mathrm{P}$, e a altura de inserção da primeira vagem somente pela inoculação.

Na ausência de inoculação, os maiores valores de IAF foram obtidos com aplicação da fonte SFT, isolada ou associada com os fosfatos naturais, porém diferindo estatisticamente apenas do controle e da fonte Itafós isolada (Tabela 2). Os resultados estão de acordo com Lynch et al. (1991) e Araújo \& Teixeira (2000), que reportaram limitações ao aumento da área foliar do feijoeiro em baixos níveis de P no substrato, fato ocorrido na ausência de aplicação e no fornecimento isolado de fontes muito pouco solúveis, como Itafós, que demoram mais a liberar o fósforo para a absorção radicular. Nesta condição, há redução na produção de folhas novas, o que pode reduzir a taxa fotossintética e afetar o crescimento da planta em estádios posteriores.

Tabela 1: Concentração de $\mathrm{P}_{2} \mathrm{O}_{5}$ total e solubilidades em $\mathrm{H}_{2} \mathrm{O}$, citrato neutro de amônio $+\mathrm{H}_{2} \mathrm{O}\left(\mathrm{CNA}+\mathrm{H}_{2} \mathrm{O}\right)$ e ácido cítrico a $2 \%$ (A.C.) relação 1:100, das fontes de P utilizadas

\begin{tabular}{lccrr}
\hline \multirow{2}{*}{ Fonte } & Total & $\mathbf{H}_{2} \mathbf{O}$ & $\left(\mathbf{C N A}+\mathbf{H}_{2} \mathbf{O}\right)$ & A.C. \\
\cline { 2 - 5 } & \multicolumn{5}{c}{$\mathbf{\%}_{\mathbf{2}} \mathbf{O}_{\mathbf{5}}$} \\
\hline SFT & 45,00 & 37,00 & 41,00 & 40,40 \\
Gafsa & 29,58 & 0 & 6,51 & 10,00 \\
Itafós & 23,17 & 0 & - & 5,50 \\
\hline
\end{tabular}

Fonte: Prochnow et al. (2004). 
A inoculação de Bacillus subtilis elevou o IAF apenas quando se aplicou a fonte SFT isoladamente (Tabela 2). Porém, para a aplicação das fontes naturais, não se constatou que a inoculação associada foi capaz de promover maior solubilização do $\mathrm{P}$ e, consequentemente, proporcionar um IAF mais próximo daquele obtido na presença de fonte solúvel.

Os resultados obtidos para MSPA foram semelhantes ao efeito observado para o IAF (Tabela 2), o que decorre da grande influência do fósforo no metabolismo energético das plantas (Taiz \& Zeiger, 2010), não só para produção de folhas, mas na própria síntese de biomassa (Fageria et al., 2003), intermediado pelo processo fotossintético.

Tanto para a massa seca de raízes (Tabela 2) quanto para o volume das mesmas (Tabela 3), as fontes diferiram apenas na presença de inoculação. Nesta condição, os valores foram maiores com o uso de SFT isolado ou combinado com Itafós, principalmente comparados ao controle e à utilização das fontes naturais isoladamente, o que reforça que a inoculação, pelo menos até o período de avaliação (florescimento), foi eficiente apenas em aumentar a disponibilidade do fósforo aplicado em formas de maior solubilidade.
$\mathrm{O}$ aumento na disponibilização do $\mathrm{P}$ pode explicar a maior massa e volume de raízes, uma vez que o nutriente é conhecido por estimular o crescimento radicular (Chaib et al., 1984; Silva \& Delatorre, 2009; Souto et al., 2009). Isto pode estar relacionado aos melhores resultados obtidos na parte aérea das plantas, como um reflexo do aumento no sistema de raízes, o que promoveu maior capacidade de absorção de água e nutrientes. Outro ponto é que a inoculação, inclusive, reduziu a MSR e VR dos tratamentos em que foram aplicadas as fontes Gafsa e Itafós de forma isolada (Tabela 3), o que pode ser resultado de uma competição pelo $\mathrm{P}$, por meio de imobilização do nutriente proveniente destas fontes de liberação mais lenta por parte das bactérias (Souza et al., 2007).

$\mathrm{Na}$ ausência de inoculação, as maiores produtividades de grãos foram obtidas nos tratamentos em que a fonte solúvel SFT esteve presente (2,84 a 4,12 g por planta), enquanto se observaram as menores médias no controle $(0,95 \mathrm{~g}$ por planta) e nas fontes naturais isoladas $(0,64 \mathrm{e}$ $1,09 \mathrm{~g}$ por planta) (Tabela 3). Os resultados evidenciam o problema da baixa eficiência dos fosfatos naturais em fornecer o fósforo de acordo com o ritmo de demanda das plantas, aliado à utilização de doses iguais para todas as

Tabela 2: Desdobramento da interação entre fontes de fósforo e inoculação com Bacillus subtilis para as características índice de área foliar (IAF), massa seca da parte aérea (MSPA) e massa seca da raiz (MR) do feijoeiro cv. IPR Colibri

\begin{tabular}{|c|c|c|c|c|c|c|}
\hline \multirow{3}{*}{ Fontes } & \multicolumn{2}{|c|}{ IAF $\left(\mathrm{cm}^{2}\right)$} & \multirow{2}{*}{\multicolumn{2}{|c|}{$\begin{array}{r}\text { MSPA (g) } \\
\text { Inoculação }\end{array}$}} & \multicolumn{2}{|c|}{ MSR (g) } \\
\hline & \multirow[b]{2}{*}{ Sem } & \multirow[b]{2}{*}{ Com } & & & & \\
\hline & & & Sem & Com & Sem & Com \\
\hline Controle & $239,74 a C^{*}$ & $286,68 \mathrm{aC}$ & $0,78 \mathrm{aC}$ & $0,76 \mathrm{aB}$ & $0,96 \mathrm{aA}$ & $0,86 \mathrm{aC}$ \\
\hline Gafsa (G) & 489,79aABC & $275,75 \mathrm{aC}$ & $2,63 \mathrm{aAB}$ & $0,89 \mathrm{bB}$ & $1,66 \mathrm{aA}$ & $0,79 \mathrm{bC}$ \\
\hline Itafós (I) & $330,03 \mathrm{aBC}$ & $267,90 \mathrm{aC}$ & $0,95 \mathrm{aBC}$ & $1,01 \mathrm{aB}$ & $1,74 \mathrm{aA}$ & $0,90 \mathrm{bC}$ \\
\hline SFT & $975,90 \mathrm{bA}$ & $1517,95 \mathrm{aA}$ & $3,25 \mathrm{bA}$ & $4,65 \mathrm{aA}$ & $1,30 \mathrm{bA}$ & $2,43 \mathrm{aA}$ \\
\hline $\mathrm{SFT}+\mathrm{G}$ & $945,54 \mathrm{aA}$ & $1141,76 \mathrm{aAB}$ & $3,62 \mathrm{aA}$ & $4,47 \mathrm{aA}$ & $1,60 \mathrm{aA}$ & $1,06 \mathrm{aBC}$ \\
\hline $\mathrm{SFT}+\mathrm{I}$ & $793,18 \mathrm{aAB}$ & $797,73 \mathrm{aB}$ & $2,23 \mathrm{aABC}$ & $2,40 \mathrm{aB}$ & $1,17 \mathrm{bA}$ & $1,87 \mathrm{aAB}$ \\
\hline C.V. $(\%)$ & & & & & & \\
\hline
\end{tabular}

* Médias seguidas da mesma letra maiúscula na coluna e minúscula na linha, não diferem estatisticamente entre si pelo teste de Tukey, a 5\%.

Tabela 3: Desdobramento da interação entre fontes de fósforo e inoculação com Bacillus subtilis para as características volume da raiz (VR) e produtividade de grãos (PROD) do feijoeiro cv. IPR Colibri

\begin{tabular}{|c|c|c|c|c|}
\hline \multirow[t]{3}{*}{ Fontes } & \multicolumn{2}{|c|}{ VR (mL) } & \multicolumn{2}{|c|}{ PROD (g por planta) } \\
\hline & \multicolumn{2}{|l|}{ Inoculação } & \multirow[b]{2}{*}{ Sem } & \multirow[b]{2}{*}{ Com } \\
\hline & Sem & Com & & \\
\hline Controle & $0,85 \mathrm{aA}^{*}$ & $0,80 \mathrm{aC}$ & $0,95 \mathrm{aB}$ & $0,71 \mathrm{aC}$ \\
\hline Gafsa $(G)$ & $1,10 \mathrm{aA}$ & $0,75 b C$ & $0,64 \mathrm{aB}$ & $1,12 \mathrm{aC}$ \\
\hline Itafós (I) & $1,17 \mathrm{aA}$ & $0,82 \mathrm{bBC}$ & $1,09 \mathrm{bB}$ & $3,28 \mathrm{aAB}$ \\
\hline SFT & $0,97 \mathrm{bA}$ & $1,40 \mathrm{aA}$ & $4,12 \mathrm{aA}$ & $4,84 \mathrm{aA}$ \\
\hline $\mathrm{SFT}+\mathrm{G}$ & $1,10 \mathrm{aA}$ & $0,87 \mathrm{aBC}$ & $2,84 \mathrm{aA}$ & $3,88 \mathrm{aAB}$ \\
\hline $\mathrm{SFT}+\mathrm{I}$ & $0,92 \mathrm{bA}$ & $1,20 \mathrm{aAB}$ & $3,03 \mathrm{aA}$ & $2,89 \mathrm{aB}$ \\
\hline C.V. $(\%)$ & \multicolumn{2}{|c|}{17,81} & \multicolumn{2}{|c|}{33,32} \\
\hline
\end{tabular}

"Médias seguidas da mesma letra maiúscula na coluna e minúscula na linha, não diferem estatisticamente entre si pelo teste de Tukey, a $5 \%$.

Rev. Ceres, Viçosa, v. 65, n.2, p. 189-195, mar/abr, 2018 

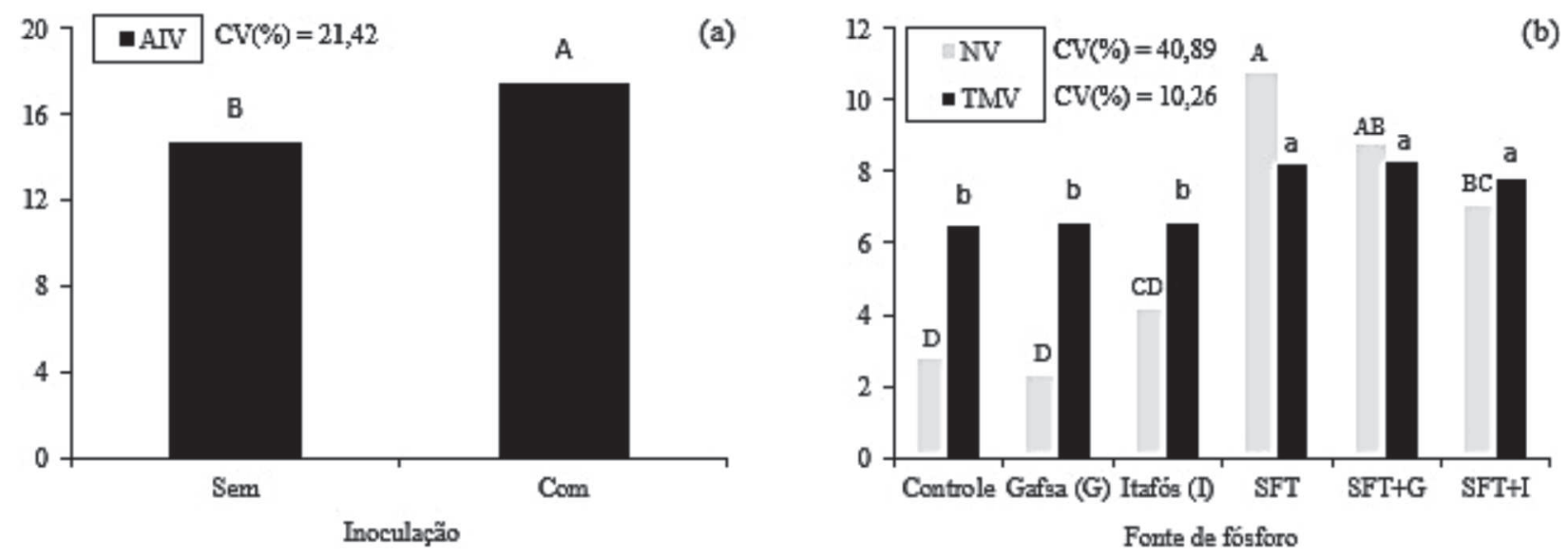

Colunas acompanhadas de mesma letra, maiúscula para AIV e NV, e minúscula para TMV, não diferem estatisticamente pelo teste de Tukey a $5 \%$.

Figura 1: Altura de inserção da primeira vagem (AIV, $\mathrm{cm}$ ) em presença ou ausência de inoculação com Bacillus subtilis (a); número de vagens por planta $(\mathrm{NV})$ e tamanho médio das vagens (TMV, $\mathrm{cm}$ ) em resposta a fontes de fósforo (b) no feijoeiro cv. IPR Colibri.

fontes, sem considerar suas especificidades, o que tem trazido grande variação nos resultados (Camargo \& Silveira, 1998). O superfosfato se sobressai pelo fato de os adubos fosfatados acidulados apresentarem solubilidades relativamente elevadas em água, razão pela qual têm alta eficiência agronômica comparativamente aos fosfatos naturais (Prochnow et al., 2004).

Apesar da menor eficiência dos fosfatos naturais, um resultado destacável na presença de inoculação foi a obtenção de elevada produtividade de grãos com o uso isolado do Itafós (3,28 g por planta), assemelhando-se estatisticamente ao uso do SFT isolado $(4,84 \mathrm{~g}$ por planta) ou associado às fontes naturais $(2,89$ e 3,88 g por planta). Ainda, apenas para o Itafós houve significativamente maior produtividade de grãos na presença $(3,28 \mathrm{~g}$ por planta) do que na ausência (1,09 g por planta) da inoculação (Tabela 3), evidenciando que, para esta fonte natural, o efeito esperado da inoculação (aumento da solubilização e disponibilização do P aplicado) se concretizou. No entanto, tal efeito para a fonte Itafós ocorreu apenas após o florescimento (uma vez que as características de crescimento avaliadas neste estádio não foram incrementadas pela inoculação), culminando em efeito positivo na produtividade. Estes resultados contrariam as afirmações de Grant et al. (2001), que argumentam que as limitações de disponibilidade no início do ciclo vegetativo podem resultar em restrições no desenvolvimento, das quais as plantas não se recuperam posteriormente, mesmo aumentando a posteriori o fósforo a níveis adequados.

A inoculação com Bacillus subtilis proporcionou aumento na altura de inserção da primeira vagem (de 14,75 para 17,50 cm) (Figura 1a), possivelmente devido à capacidade de as bactérias promoverem o crescimento das plan- tas por meio da produção de fitormônios de crescimento como auxinas e giberelinas, conforme observado por autores como Mariano et al. (2004), Araújo \& Pedroso (2013) e Costa et al. (2014).

O uso isolado do SFT proporcionou número de vagens superior, sem, contudo, diferir da sua aplicação associada com Gafsa. Também, SFT e suas combinações com os fosfatos naturais promoveram vagens de maior tamanho (Figura 1b). Estes resultados são reflexo do melhor crescimento vegetativo que os referidos tratamentos proporcionaram às plantas, em termos de área fotossintetizante e produção de biomassa (Tabela 2), dando suporte à formação de estruturas reprodutivas (Taiz \& Zeiger, 2010). Para o número de grãos por vagem, contudo, não foi possível observar diferença entre as fontes e nem efeito de inoculação, obtendo-se em média 3,45 grãos por vagem (C.V. $=21,84 \%$ ), mesmo no controle sem aplicação do nutriente. Zucareli et al. (2006), também observaram que apesar de a adubação fosfatada influenciar positivamente o número de vagens por planta do feijoeiro cv. IAC carioca, o número de grãos por vagem não foi alterado, inclusive na ausência de aplicação de P.

\section{CONCLUSÕES}

A adubação fosfatada envolvendo a fonte solúvel superfosfato triplo (SFT), isolada ou combinada com fontes naturais, favorece o crescimento e o desempenho produtivo do feijoeiro. A associação dessa fonte de P com a inoculação de Bacillus subtilis promove maior crescimento de raízes e parte aérea, porém sem efeitos na produtividade de grãos.

A combinação do SFT com os fosfatos de Gafsa e Itafós potencializa o uso das fontes naturais, melhorando as 
características relacionadas ao crescimento e desempenho produtivo das plantas quando comparado às suas utilizações isoladas.

Há um aumento expressivo na produtividade de grãos para o uso de Itafós quando associado à inoculação, o que demonstra a capacidade das bactérias em elevar a disponibilização do fósforo desta fonte em estádios mais avançados do desenvolvimento.

\section{REFERÊNCIAS}

Araújo AP \& Teixeira MG (2000) Ontogenetic variations on absorption and utilization of phosphorus in common bean cultivars under biological nitrogen fixation. Plant and Soil, 225:01-10.

Araújo FF \& Pedroso RAB (2013) Interação de Bacillus sp. com a rizosfera de três espécies de plantas forrageiras. Bioscience Journal, 29:152-158.

Brasil - Ministério da Agricultura, Pecuária e Abastecimento (2007) Instrução Normativa ${ }^{\circ} 5$, de 23 de fevereiro de 2007. Definições e normas sobre as especificações e as garantias, as tolerâncias, o registro, a embalagem e a rotulagem dos fertilizantes minerais, destinados à agricultura. DOU, 01/03/2007, Seção 1 , p. 38.

Camargo MS \& Silveira RI (1998) Efeitos dos fosfatos naturais alvorada, catalão, patos e arad na produção de massa seca de milho em casa-de-vegetação. Scientia Agricola, 55:509-519.

Chabot R, Antoun H \& Cescas MP (1996) Growth promotion of maize and lettuce by phosphate-solubilizing Rhizobium leguminosarum biovar. phaseoli. Plant and Soil, 184:311-321.

Chaib SL, Bulisani EA \& Castro LHSM (1984) Crescimento e produção do feijoeiro em resposta à profundidade de aplicação do adubo fosfatado. Pesquisa Agropecuária Brasileira, 19:817822 .

Coelho LF, Freitas SS, Melo AMT \& Ambrosano GMB (2007) Interação de bactérias fluorescentes do gênero Pseudomonas e Bacillus spp. com rizosferas de diferentes plantas. Revista Brasileira de Ciência do Solo, 31:1413-1420.

Costa EM, Carvalho F, Esteves JA, Nóbrega RSA \& Moreira FMS (2014) Resposta da soja a inoculação e co-inoculação com bactérias promotoras do crescimento vegetal e Bradyrhizobium. Enciclopédia Biosfera, 10:1678-1689.

Cunha DA, Teixeira IR, Jesus FF, Guimarães RT \& Teixeira GCS (2014) Adubação fosfatada e produção de feijão-comum e mamona em consórcio. Bioscience Journal, 30:617-628.

Embrapa - Empresa Brasileira de Pesquisa Agropecuária (2013) Sistema brasileiro de classificação de solos. $3^{a}$ ed. Rio de Janeiro, Embrapa Solos. 353p.

Fageria NK, Barbosa Filho MP \& Stone LF (2003) Resposta do feijoeiro a adubação fosfatada. Piracicaba, Potafós. (Informações Agronômicas, 102).

Ferreira DF (2011) Sisvar: a computer statistical analysis system. Ciência \& Agrotecnologia, 35:1039-1042.

Franzini VI, Muraoka T, León HMC \& Mendes FL (2009) Eficiência de fosfato natural reativo aplicado em misturas com superfosfato triplo em milho e soja. Pesquisa Agropecuária Brasileira, 44:1092-1099.

Grant CA, Flaten DN, Tomasiewicz DJ \& Sheppard SC (2001) A importância do fósforo no desenvolvimento inicial da planta. Piracicaba, Potafós. 5p. (Informações Agronômicas, 95).
Gaind S \& Gaur AC (1991) Thermotolerant phosphate solubilizing microorganisms and their interaction with mung bean. Plant and Soil, 133:141-149.

IAPAR - Instituto Agronômico do Paraná (2016) Médias históricas. Disponível em: http:www.iapar.br/arquivos/Image/ monitoramento/Medias_Historicas/Londrina.htm. Acessado em: 12 de março de 2016.

Korndörfer GH, Lara-Cabezas WA \& Horowitz N (1999) Eficiência agronômica de fosfatos naturais reativos na cultura do mi1ho. Scientia Agricola, 56:391-396.

Lynch J, Läuchli A \& Epstein E (1991) Vegetative growth of the common bean in response to phosphorus nutrition. Crop Science, 31:380-387.

Mariano RLR, Silveira EB, Assis SMP, Gomes AMA, Nascimento ARP \& Donato VMTS (2004) Importância de bactérias promotoras de crescimento e de biocontrole de doenças de plantas para uma agricultura sustentável. Anais da Academia Pernambucana de Ciências Agronômicas, 1:89-111.

Oliveira Júnior A, Prochnow LI \& Klepker D (2011) Soybean yield in response to application of phosphate rock associated with triple superphosphate. Scientia Agricola, 68:376-385.

Pantano G, Grosseli GM, Mozeto AA \& Fadini PS (2016) Sustentabilidade no uso do fósforo: uma questão de segurança hídrica e alimentar. Química Nova, 39:732-740.

Pegoraro RF, Oliveira D, Moreira CG, Kondo MK \& Portugal AF (2014) Partição de biomassa e absorção de nutrientes pelo feijoeiro comum. Revista Caatinga, 27:41-52.

Piaia FL, Rezende PM, Furtini Neto AE, Fernades LA \& Corrêa JB (2002) Eficiência da adubação fosfatada com diferentes fontes e saturações por bases na cultura da soja [Glycine max (L.) Merrill]. Ciência \& Agrotecnologia, 26:488-499.

Prochnow LI, Alcarde JC \& Chien SH (2004) Eficiência agronômica dos fosfatos totalmente acidulados In: Yamada T \& Abdalla SRS (Eds.) Simpósio sobre fósforo na agricultura brasileira. São Paulo, Associação Brasileira para Pesquisa da Potassa e do Fosfato. p.605-663.

Rodriguez H \& Fraga R (1999) Phosphate solubilizing bacteria and their role in plant growth promotion. Biotechnology Advances, 17:319-339.

Richardson AE (2001) Prospects for using soil microorganisms to improve the acquisition of phosphorus by plants. Australian Journal of Plant Physiology, 28:897-906.

Silva AA \& Delatorre CA (2009) Alterações na arquitetura de raiz em resposta à disponibilidade de fósforo e nitrogênio. Revista de Ciências Agroveterinárias, 8:152-163.

Souto JS, Oliveira FT, Gomes MMS, Nascimento JP \& Souto PC (2009) Efeito da aplicação de fósforo no desenvolvimento de plantas de feijão guandu (Cajanus cajan (L) Mill sp). Revista Verde, 4:135-140.

Souza CES, Silva MO, Duda GP \& Mendes MAS (2007) Solubilização de fósforo de fertilizantes fosfatados após tratamento com diferentes resíduos orgânicos. Revista de Biologia e Ciências da Terra, 7:120-126.

Taiz L \& Zeiger E (2010) Plant Physiology. 5a ed. Sunderland, Sinauer Associates. 781p.

Valderrama M, Buzetti S, Benett CGS, Andreotti M, Arf O \& Sá ME (2009) Fontes e doses de nitrogênio e fósforo em feijoeiro no sistema plantio direto. Pesquisa Agropecuária Tropical, 39:191-196.

Valladares GS, Pereira MG \& Dos Anjos LHC (2003) Adsorção de fósforo em solos de argila de atividade baixa. Bragantia, 62:111118.

Rev. Ceres, Viçosa, v. 65, n.2, p. 189-195, mar/abr, 2018 
Viana TO, Vieira NMB, Moreira GBL, Batista RO, Carvalho SJP \& Rodrigues HFF (2011) Adubação do feijoeiro cultivado no norte de Minas Gerais com nitrogênio e fósforo. Revista Ceres, 58:115-20.

Zucareli C, Junior EUR, Barreiro AP, Nakagawa J \& Cavariani C (2006) Adubação fosfatada, componentes de produção, produtividade e qualidade fisiológica em sementes de feijão. Revista Brasileira de Sementes, 28:09-15. 